\title{
Predictors of difficult intubation defined by the intubation difficulty scale (IDS): predictive value of 7 airway assessment factors
}

\author{
Suk-Hwan Seo, Jeong-Gil Lee, Soo-Bong Yu, Doo-Sik Kim, Sie-Jeong Ryu, and Kyung-Han Kim \\ Department of Anesthesiology and Pain Medicine, Kosin University College of Medicine, Busan, Korea
}

Background: The intubation difficulty scale (IDS) has been used as a validated difficulty score to define difficult intubation (DI). The purpose of this study is to identify airway assessment factors and total airway score (TAS) for predicting DI defined by the IDS.

Methods: There were 305 ASA physical status 1-2 patients, aged 19-70 years, who underwent elective surgery with endotracheal intubation. During the pre-anesthetic visit, we evaluated patients by 7 preoperative airway assessment factors, including the following: Mallampati classification, thyromental distance, head \& neck movement, body mass index (BMI), buck teeth, inter-incisor gap, and upper lip bite test (ULBT). After endotracheal intubation, patients were divided into 2 groups based on their IDS score estimated with 7 variables: normal (IDS $<5$ ) and DI (IDS $\geq 5$ ) groups. The incidence of TAS $(>6)$ and high score of each airway assessment factor was compared in two groups: odds ratio, confidence interval (CI) of $95 \%$, with a significant $\mathrm{P}$ value $\leq 0.05$.

Results: The odds ratio of TAS $(>6)$, ULBT (class III), head \& neck movement $\left(<90^{\circ}\right)$, inter-incisor gap $(<4 \mathrm{~cm}), \mathrm{BMI}(\geq$ $25 \mathrm{~kg} / \mathrm{m}^{2}$ ) and Mallampati classification ( $\geq$ class III) were respectively 13.57 (95\% CI = 2.99-61.54, P < 0.05), $12.48(95 \%$ $\mathrm{CI}=2.50-62.21, \mathrm{P}<0.05), 3.11(95 \% \mathrm{CI}=0.87-11.13), 2.32(95 \% \mathrm{CI}=0.75-7.19), 2.22(95 \% \mathrm{CI}=0.81-6.06)$, and 1.22 $(95 \% \mathrm{CI}=0.38-3.89)$.

Conclusions: We suggest that TAS $(>6)$ and ULBT (class III) are the most useful factors predicting DI. (Korean J Anesthesiol 2012; 63: 491-497)

Key Words: Anesthesia, Evaluation studies, Intubation.

Received: January 30, 2012. Revised: 1st, April 15, 2012; 2nd, June 11, 2012. Accepted: June 15, 2012.

Corresponding author: Kyung-Han Kim, M.D., Department of Anesthesiology and Pain Medicine, Kosin University College of Medicine, Amnamdong, Seo-gu, Busan 602-702, Korea. Tel: 82-51-990-6283, Fax: 82-51-254-2504, E-mail: kimkh@ns.kosinmed.or.kr

(c) This is an open-access article distributed under the terms of the Creative Commons Attribution Non-Commercial License (http:// creativecommons.org/licenses/by-nc/3.0/), which permits unrestricted non-commercial use, distribution, and reproduction in any medium, provided the original work is properly cited. 


\section{Introduction}

Difficult endotracheal intubation under general anesthesia can cause intubation delay or failure, which can bring on fatal results. Thus, there have been many studies that have reported on various criteria for airway assessment to predict difficult endotracheal intubation before anesthesia [1-9]. There may be various definitions for difficult intubation. Among them, Benumof reported on many cases where difficult endotracheal intubation occurred in $1-4 \%$ of cases, and intubation failure occurred $0.05-0.35 \%$ of cases [5]. Benumof defined difficult endotracheal intubation as Cormack and Lehan grade III with several attempts made and defined intubation failure as Cormack and Lehan grade III or IV with failure [5]. The American Society of Anesthesiologists (ASA) defines difficult endotracheal intubation as 3 attempts at endotracheal intubation when an average laryngoscope is used or when endotracheal intubation takes $10 \mathrm{~min}$ or more [10]. However, with the above criteria, the incidence of difficult endotracheal intubation is low and the sample size is too small to make an experimental group for predicting the difficulty of endotracheal intubation. Also, although ASA's definition of difficult endotracheal intubation can tell whether the intubation is difficult or not, but difficult intubation is very subjective and it is difficult to measure the degree of difficulty. Thus, Adnet et al. created an intubation difficulty scale (IDS) that has objective categories on difficulty of an endotracheal intubation was after it was performed: easy endotracheal intubation, slightly difficult endotracheal intubation, and very difficult endotracheal intubation [11]. There have not yet been any studies in Korea on assessing the difficulty of intubation using IDS, so the authors have used IDS to objectively assess and quantify the difficulty of endotracheal intubation.

Normally to predict difficult endotracheal intubation before anesthesia, the criteria that assess physical characteristics, such as the Wilson score and the LEMON method, have been used to make airway assessments, but depending on the author and research method, the results have been very different [3,6-9]. The authors here have come up with 7 factors for airway evaluation to use for predicting difficult endotracheal intubation; they include some of the Wilson score, body mass index (BMI), and the upper lip bite test (ULBT) [12].

The purpose of the present study was that patients were divided by their IDS score into the difficult intubation (DI) group and the normal (N) group, and the 7 airway assessment factors and their total airway score (TAS), which is the sum of the all the factors, were compared in the 2 groups so that a method that effectively predicts difficult endotracheal intubation could be provided.

\section{Materials and Methods}

After passing the Institutional Review Board, the study was performed at the hospital on 305 ASA I and II patients between the ages 19 years and 70 years, who were scheduled for surgery under general anesthesia. Patients were excluded from the study if their teeth were incomplete, if the patient had limited head and neck movement, had impairment of the temporomandibular joint, or had oral or laryngeal tumor. After the purpose of airway assessment was explained to patients, their consent was obtained. Two second-year anesthesiology residents visited the patients before their surgeries to evaluate the airway assessment factors and to record them on a separate piece of paper. The 7 airway assessment factors were the following: Mallampati classification, the thyromental distance, the head \& neck movement, BMI, the severity of buck teeth, the interincisor gap, and the ULBT. Each factor was given a 0 , 1, or 2 points (for BMI, 0 or 1 point), and the total score was tallied and recorded as TAS (Table 1 ).

The study methodology for the airway assessment factors was as follows: first, the Mallampati classification provided up to class III. Level IV was added from Samsoon and Young's classification (1987) [2]. The patient was put in the sitting position with the head in the neutral position, and the mouth was opened, as widely as possible. The patient stuck his/her tongue out of his/her mouth if possible. The observer used a penlight to observe the pharyngeal structure. After the patient relaxed, observation was made again to decide upon the score [6]. Second, the thyromental distance was measured when the patient extended his neck, the distance from the thyroid notch to the end of the chin was measured using 3 knuckles (approximately 6-6.5 cm). Third, the head and neck movement range was measured by making the patient extend their neck as much as possible. Then, while holding a pen vertically to the patient's forehead, a notepad has held against the side of the patient's face next to the pen. Then, the patient's neck was flexed as much as possible. If the pencil was parallel to the bottom side of the notepad, it was recorded as $90^{\circ}$. If the pencil

Table 1. Rules for Evaluating Airway Score

\begin{tabular}{lccc}
\hline \multirow{2}{*}{\multicolumn{1}{c}{ Airway factors }} & \multicolumn{3}{c}{ Score } \\
\cline { 2 - 4 } & 0 & 1 & 2 \\
\hline Mallampati classification & Class I & Class II & Class III-IV \\
Thyromental distance $(\mathrm{cm})$ & $>6.5$ & $6-6.5$ & $<6$ \\
Head $\&$ neck movement $\left(^{\circ}\right)$ & $>90$ & 90 & $<90$ \\
BMI $\left(\mathrm{kg} / \mathrm{m}^{2}\right)$ & $<25$ & $\geq 25$ & - \\
Buck teeth & No & Mild & Severe \\
Inter-incisor gap $(\mathrm{cm})$ & $>5$ & $4-5$ & $<4$ \\
ULBT & Class I & Class II & Class III \\
\hline
\end{tabular}

BMI: body mass index, ULBT: upper lip bite test. 
was lower than the bottom side of the notepad, it was recorded as more than $90^{\circ}$ [6]. Fourth, if BMI was $25 \mathrm{~kg} / \mathrm{m}^{2}$ or more, 1 point was given; if BMI was below $25 \mathrm{~kg} / \mathrm{m}^{2}, 0$ points were given. Fifth, the severity of buck teeth was considered normal if the patient put his teeth together, and the upper teeth closed on the lower teeth without space. If the upper teeth protruded $0-0.5$ $\mathrm{cm}$ more than the lower teeth, it was considered moderate. If the upper teeth protruded more than $0.5 \mathrm{~cm}$ compared to the lower teeth, it was considered severe. Sixth, the inter-incisor gap was measured by taking the distance between the upper and lower teeth when the mouth was opened as widely as possible. Lastly, the ULBT was done in the upright sitting position with the jaw protruded, and the ability of the lower teeth to bite the upper lip was recorded as 3 classes. Class I was when the lower teeth was able to bite the upper vermillion line and completely cover the upper lip membrane. Class II was when the lower teeth bit below the upper vermillion line so that only some of the membrane was covered. Class III was when the lower teeth could not bite the upper lip [13].

In addition to the previous parameters mentioned, the prevalence of hypertension and diabetes was studied to see the effects of chronic diseases on the difficulty of endotracheal intubation.

After arriving at the operating theatre, ASA standard monitoring devices were attached to start monitoring the patient. Before anesthetic induction, for oxygenation $100 \%$ oxygen $\left(\mathrm{FiO}_{2} 1.0\right)$ was administered and for a minimum $3 \mathrm{~min}$, the patient was made to breathe voluntarily. For premedication, $0.2 \mathrm{mg}$ glycopyrrolate was administered intravenously, for anesthetic induction the patient was administered $0.05 \mathrm{mg} /$ $\mathrm{kg}$ midazolam, $1 \mathrm{mg} / \mathrm{kg}$ propofol intravenously, and $0.2 \mathrm{ug} /$ $\mathrm{kg} / \mathrm{min}$ remifentanil by continuous IV. After checking for loss

Table 2. Rules for Calculating IDS Score

\section{Calculating method}

\footnotetext{
$\mathrm{N}_{1} \quad$ Every additional attempt adds 1 point

$\mathrm{N}_{2} \quad$ Each additional operator adds 1 point

$\mathrm{N}_{3}$ Each alternative technique adds 1 point: repositioning of the patient, change of materials (blade, ET tube, addition of a stylette), change in approach (nasotracheal/orotracheal) or use of another technique (fibroscopy, intubation through a laryngeal mask)

$\mathrm{N}_{4} \quad$ Apply Cormack grade for 1 st oral attempt. For successful blind intubation: $\mathrm{N}_{4}=0$

$\mathrm{N}_{5}$ Increased lifting force during laryngoscopy adds 1 point. For normal lifting force: $\mathrm{N}_{5}=0$

$\mathrm{N}_{6} \quad$ External laryngeal pressure to improve glottic exposure adds 1 point

$\mathrm{N}_{7}$ Position of vocal cords during laryngoscopy (abduction: $\mathrm{N}_{7}=$ 0 , adduction: $\mathrm{N}_{7}=1$ )
}

ET: endotracheal, IDS: intubation difficulty scale (IDS $=0$ : easy, $0<$ IDS $\leq 5$ : slight difficulty, IDS $>5$ : moderate to severe difficulty). of consciousness, $0.8 \mathrm{mg} / \mathrm{kg}$ rocuronium was administered intravenously. After checking full muscle relaxation, the patient was put into the sniffing position, and endotracheal intubation was performed. For laryngoscopy, a Macintosh blade 3-5 was chosen depending on the body frame, and an intubation introducer was used routinely for intubation. Intubation time was the time it took from when the mask was removed and the patient's mouth was opened to when the patient was intubated and the first capnography waveforms appeared. During intubation, the lowest $\mathrm{SpO}_{2}$ value was measured and recorded. The whole intubation process was scored by using 7 measuring variables of the IDS (Table 2).

The 7 measuring variables of the IDS $\left(\mathrm{N}_{1}-\mathrm{N}_{7}\right)$ consist of the number of intubation attempts, the number of additional procedures, the use of different intubation skills, Cormack and Lehane's classification of laryngeal view, the lifting force when laryngoscopy is used, external laryngeal pressure maneuver, and the location of the vocal cord under laryngoscopic view [11]. The evaluation method for IDS was as follows: for $\mathrm{N}_{1}$, if intubation was successful on the first time, 0 points were given, and 1 point was added with additional intubation attempts. For $\mathrm{N}_{2}, 1$ point was added with the increase of the number of doctors for endotracheal intubation. For $\mathrm{N}_{3}, 1$ point was added with the repositioning of patients or with a change in intubation technique, such as a blade or a tube change. For $\mathrm{N}_{4}$, grade 1 in Cormack and Lehane's classification on laryngeal view was 0 points, and 1 point was given with the increase in classification grade. For $\mathrm{N}_{5}$, if the lifting force was normal with the use of laryngoscopy, 0 points were given. If a lot of force was needed, 1 point was added. For $\mathrm{N}_{6}$, if external laryngeal pressure maneuver was needed to see the glottis better, 1 point was added. For $\mathrm{N}_{7}$, if the vocal cord under laryngoscopic view was abducted, 0 points were given. If the vocal cord was adducted, 1 point was added. The 3 classifications (Table 2) were as follows: if the IDS sum of the 7 measuring variables was 0 points, then it was considered an easy endotracheal intubation. If the score was $1-5$ points, it was a slightly difficult intubation. More than 5 points was considered moderate-to-difficult intubation.

There are 3 groups with IDS. However in the present study, to see the relevance of preoperative airway assessment score, an IDS score of 5 points or more was considered to belong to the difficult endotracheal intubation group. Below 5 points was slightly difficult intubation, and these patients were put into the contrast group. In the airway assessment point system, if TAS was over 6 points, it was considered that difficult endotracheal intubation was predicted. The 7 airway assessment factors (each factor was worth 2 points; BMI was worth 1 point) and TAS more than 6 points of the two groups were compared to find P-value and the odd ratio. The differences in the prevalence of hypertension, diabetes, the intubation time, and the lowest 
$\mathrm{SpO}_{2}$ value during intubation were also studied.

For statistical analysis, SPSS (Version 18.0) was used. The comparison of the TAS and airway assessment factors were done by calculating the $\mathrm{P}$ value using the chi-square test. Age, sex, the prevalence of hypertension and diabetes, intubation time, and the lowest $\mathrm{SpO}_{2}$ value were compared by finding $P$ value using student's t-test or chi-square test. TAS and the airway assessment factors, which showed a significant difference in the chi-square test, were again analyzed to find the odds ratio (OR), 95\% confidence interval, and $P$ value by a multivariate logistic regression analysis. A $\mathrm{P}<0.05$ was considered statistically significant.

\section{Results}

Among the total 305 patients, in the difficult intubation (DI) group, which had an IDS $>5$, there were 36 patients $(11.8 \%)$; in the normal (N) group, which had IDS $\leq 5$, there were 269 patients $(88.2 \%)$. There were no failures of intubation. TAS ranged from $1-11$ points. The mean TAS was $6.47 \pm 1.26$ in the DI group, and $2.50 \pm 1.89$ in the $\mathrm{N}$ group. There was a significant difference between the 2 groups $(\mathrm{P}<0.001)$ (Table 3$)$. In the DI group there were 25 patients $(69.4 \%)$ with TAS over 6 points, and

Table 3. Characteristics of Patients in the Normal and DI Groups

\begin{tabular}{lccc}
\hline & $\mathrm{N}$ & $\mathrm{DI}$ & \\
& $(\mathrm{IDS}=5)$ & P value \\
& $269(88.2)$ & $36(11.8)$ & - \\
\hline Number of patients (\%) & $47.1 \pm 15.7$ & $53.2 \pm 10.6$ & 0.004 \\
Age (yr) & $126 / 143$ & $22 / 14$ & 0.108 \\
Gender (M/F) & $60(22.3)$ & $11(30.6)$ & 0.271 \\
Patients of hypertension (\%) & $40(14.9)$ & $9(25.0)$ & 0.120 \\
Patients of diabetes (\%) & $40.65 \pm 12.20$ & $72.08 \pm 10.03<0.001$ \\
Intubation duration (sec) & $99.55 \pm 1.17$ & $95.17 \pm 3.72$ & $<0.001$ \\
Lowest SaO2 level (\%) & $2.50 \pm 1.89$ & $6.47 \pm 1.26$ & $<0.001$ \\
TAS (1-11) & & \\
\hline
\end{tabular}

TAS: total airway score, N: normal, DI: difficult intubation.

Table 4. A Comparison of Airway Factors between the Normal and Difficult Intubation Groups

\begin{tabular}{lccr}
\hline \multicolumn{1}{c}{ Airway factors } & $\begin{array}{c}\mathrm{N} \\
(\mathrm{n}=269)\end{array}$ & $\begin{array}{c}\mathrm{DI} \\
(\mathrm{n}=36)\end{array}$ & P value \\
\hline TAS $(>6)$ & $7(2.6 \%)$ & $25(69.4 \%)$ & $<0.001$ \\
Mallampati classification & $47(17.5 \%)$ & $21(58.3 \%)$ & $<0.001$ \\
$(\geq$ Class III) & & & \\
Thyromental distance $(<6 \mathrm{~cm})$ & $9(3.3 \%)$ & $4(11.1 \%)$ & 0.054 \\
Head \& neck movement $\left(<90^{\circ}\right)$ & $15(5.6 \%)$ & $9(25.0 \%)$ & 0.001 \\
BMI $\left(\geq 25 \mathrm{~kg} / \mathrm{m}^{2}\right)$ & $94(34.9 \%)$ & $24(66.7 \%)$ & $<0.001$ \\
Buck teeth $(>0.5 \mathrm{~cm})$ & $13(4.8 \%)$ & $6(16.7 \%)$ & 0.063 \\
Inter-incisor gap $(<4 \mathrm{~cm})$ & $28(10.4 \%)$ & $18(50.0 \%)$ & $<0.001$ \\
ULBT $(=$ Class III) & $4(1.5 \%)$ & $12(33.3 \%)$ & $<0.001$ \\
\hline
\end{tabular}

TAS: total airway score, BMI: body mass index, ULBT: upper lip bite test, N: normal, DI: difficult intubation. there were 7 patients $(2.6 \%)$ in the $\mathrm{N}$ group. The DI group had a significantly greater number of patients with TAS over 6 points $(\mathrm{P}<0.001)$ (Table 4$)$. The odds ratio of TAS $>6$ points compared to TAS $\leq 6$ points was $13.57(95 \% \mathrm{CI}=2.99-61.54, \mathrm{P}<0.05)$. The probability of difficult intubation was 13.57 times as great (Table 5).

The authors compared the 2 groups' airway assessment factors, which were each worth 2 points (or 1 point for BMI), and found the following: the Mallampati classification( $\geq$ class III, the N group: $17.5 \%$ vs. the DI group: $58.3 \%$ ) and head and neck movement range $\left(<90^{\circ}\right.$, the $\mathrm{N}$ group: $5.6 \%$ vs. the DI group: $25.0 \%$ ), BMI ( $\geq 25 \mathrm{~kg} / \mathrm{m}^{2}$, the N group: $34.9 \%$ vs. the DI group: $66.7 \%$ ), the inter-incisor gap ( $<4 \mathrm{~cm}$, the $\mathrm{N}$ group: $10.4 \%$ vs. the DI group: $50.0 \%$ ), and the ULBT (class III, the N group: $1.5 \%$ vs. the DI group: $33.3 \%$ ). The 5 factors were significantly greater in the DI group ( $\mathrm{P}<0.05)$ (Table 4). The 5 airway assessment factors were significantly different, and their odds ratio for ULBT (class III) was 12.48 (95\% CI $=2.50-62.21, \mathrm{P}<0.05)$. For the head and neck movement range $\left(<90^{\circ}\right)$, inter-incisor gap $(<$ $4 \mathrm{~cm}$ ), BMI ( $\geq 25 \mathrm{~kg} / \mathrm{m}^{2}$ ), and Mallampati classification ( $\geq$ class III) were respectively $3.11(95 \% \mathrm{CI}=0.87-11.13, \mathrm{P}=0.081), 2.32$ (95\% CI = 0.75-7.19, P = 0.144), $2.22(95 \% \mathrm{CI}=0.81-6.06, \mathrm{P}=$ $0.120), 1.22(95 \% \mathrm{CI}=0.38-3.89, \mathrm{P}=737)$ (Table 5).

The mean age in the DI group was 53 , which was significantly greater than the $\mathrm{N}$ group's age, which was $47(\mathrm{P}<0.05)$. The endotracheal intubation time for the DI group was $72.08 \pm 10.03$ $\mathrm{s}$, which was longer than the endotracheal intubation time in the $\mathrm{N}$ group, which was $40.65 \pm 12.20$ s. During extubation, the lowest $\mathrm{SpO}_{2}$ value was $95.17 \pm 3.72 \%$ in the DI group. The $\mathrm{N}$ group showed a statistically significant difference (99.55 \pm $1.17 \%)$. Sex, the prevalence of hypertension, and diabetes were not statistically significantly different between the 2 groups (Table 3).

\section{Discussion}

In the results of the presented study, if TAS of the airway assessment factor was more than 6 points or if the ULBT was

Table 5. Airway Factors for Difficult Intubation by Multivariate Logistic Regression Analysis

\begin{tabular}{lccc}
\hline \multicolumn{1}{c}{ Airway factors } & P value & Odd ratio & 95\% CI \\
\hline TAS $(>6)$ & 0.001 & 13.57 & $2.99-61.54$ \\
ULBT (Class III) & 0.002 & 12.48 & $2.50-62.21$ \\
Head \& neck movement $\left(<90^{\circ}\right)$ & 0.081 & 3.11 & $0.87-11.13$ \\
Inter-incisor gap $(<4 \mathrm{~cm})$ & 0.144 & 2.32 & $0.75-7.19$ \\
BMI $\left(\geq 25 \mathrm{~kg} / \mathrm{m}^{2}\right)$ & 0.120 & 2.22 & $0.81-6.06$ \\
Mallampati classification & 0.737 & 1.22 & $0.38-3.89$ \\
( $\geq$ Class III) & & & \\
\hline
\end{tabular}

TAS: total airway score, ULBT: upper lip bite test, BMI: body mass index, CI: confidence interval. 
class III, the prediction of difficult endotracheal intubation was possible. There have been many methods that have attempted to predict difficult endotracheal intubation. Among them, the Wilson score and the LEMON method are commonly used. The Wilson score rates and gives the total score of 5 physical characteristics $[3,4]$, which are weight, head and neck movement, jaw movement, receding mandible, and protruding maxillary anterior teeth. Each factor is given 0 , 1, or 2 points, and the total score for the 5 can predict difficult endotracheal intubation $[3,4]$. The LEMON method stands for the 5 following parameters: Look (facial impairment, large front teeth, large tongue, beard/moustache), Evaluate (3-3-2 rule: inter-incisor gap, mental-hyoid distance, hyoid-thyroid distance), the Mallampati score, Obstruction, and Neck mobility $[8,9]$. The LEMON method can be used in emergency situations for simple and prompt difficult endotracheal intubation by looking and using fingers to measure lengths without using special tools.

Kim et al. [6] came up with a total airway score of 7 airway assessment factors by adding the Mallampati classification, thyromental distance, and a past history of difficult endotracheal intubation to the Wilson score. They stated that the 4 following factors were significant: TAS, the Mallampati classification, the thyromental distance, the head and neck movement, and the past history of difficult endotracheal intubation. In the present study, the past history of difficult endotracheal intubation was excluded and the ULBT was added, and weight was replaced with BMI in the 7 factors determined by Kim et al. As a result, out of TAS and the seven factors, the point where the Mallampati classification and the head and heck movement had significance coincided, but unlike Kim et al., BMI, the inter-incisor gap, and the ULBT showed a significant difference $(\mathrm{P}<0.05)$.

TAS was the most significant predictor of difficult endotracheal intubation. If TAS was greater than 6 points, the risk of difficult endotracheal intubation was 13.57 times as great $(95 \%$ $\mathrm{CI}=2.99-61.54, \mathrm{P}<0.05$, Table 5). TAS 6 points became the basis for predicting the risk of difficult endotracheal intubation because the odds ratio was highest at 6 points among TAS 5 , 6 , and 7 points. TAS is the sum of all the airway assessment factors, so compared to separate factors, TAS was more useful in predicting the DI group. However, the drawback is that when all 7 factors could not be found, TAS could not be calculated either.

In the present study, the odds ratio of the ULBT (class III) was 12.48 , which is high and similar to TAS $(95 \% \mathrm{CI}=2.50-2.21$, $\mathrm{P}<0.05$, Table 5). This signifies that when the ULBT was class III, the odds of difficult endotracheal intubation increased 12.48 times compared to when the ULBT was class II. Therefore, the ULBT can stand alone as a single factor for airway assessment and can be useful for predicting difficult endotracheal intubation.

The ULBT is divided into 3 grades on the ability of the lower teeth to bite the upper teeth [12]. If the patient had a receding mandible, if the patient had buck teeth, or if the patient could not open his/her mouth very well, the ULBT class appeared high. With buck teeth, it is difficult to pull down the upper lip, and if the patient has a receding mandible the movement of the jaw is difficult. Thus, the ULBT class appears high. The ULBT is considered the best method for prediction as it also checks 3 of the airway assessment factors. It is a simple testing method for assessing endotracheal intubation difficulty that can be done quickly, and it is used especially in emergency patients where airway evaluation cannot be done prior to surgery in the operating room before anesthesia. Khan et al. [12] stated that the ULBT can be used as a reliable single test and is highly trusted, because it can predict difficult endotracheal intubation better and has clearer defined classes than the Mallampati classification. However, the ULBT is not possible when the patient has dentures. In addition, individual differences in the length of the philtrum and the sucking movement of the upper lip into the oral space lead to differences in ULBT classes [13]. The authors also experienced changes in classification, because patients did not know the exact method of the ULBT. Before the patients were evaluated, clear explanations and demonstrations were provided. After this occurred, there were hardly any grading changes.

Kim et al. [6] stated that weight (kg) is not a significant predictor of difficult endotracheal intubation. Lavi et al. [14] had normal and obese patients classified according to their BMI to compare the difficulty of intubation, and they found that the IDS was significantly higher in obese patients. Thus, the authors added BMI instead of weight (kg) to the Wilson score and compared the DI group to the N group. The results in the chisquare test showed that BMI was significantly different between the two groups. In the multi regression analysis, the odds ratio of BMI was 2.22. Difficult intubation for BMI $\geq 25 \mathrm{~kg} / \mathrm{m}^{2}$ was twice as great as BMI $<25 \mathrm{~kg} / \mathrm{m}^{2}$. But the multiple regression analysis did not have a significant $P$ value and a 95\% confidence interval, so it cannot alone be used a predictor (Table 4 and 5). Usually obese patients commonly have hypertension and diabetes, but they did not appear significantly different in the 2 groups presented (Table 3). However, Lavi et al. [14] stated that they showed a significant difference in the obese group compared to the normal group. Such differences may be due to the fact that Lavi et al's study was based on an obesity standard set for Western patients. The WHO defines obesity as a BMI $=30 \mathrm{~kg} / \mathrm{m}^{2}$ or more [15]. But the present study was based on Asia's obesity standard, which is a BMI $=25 \mathrm{~kg} / \mathrm{m}^{2}[16]$.

The Mallampati classification has been used for a long time for predicting difficult endotracheal intubation. It was reported that Mallampati class III and IV have a significant correlation with predicting difficult endotracheal intubation [17]. However, 
the patients' compliance in positioning and phonation, as well as the evaluator's assessment of the oral structure can produce different results [18]. The present study found a significant difference in the Mallampati classification between the 2 groups when using the chi-square test. However, with the multiple regression analysis, the odds ratio was 1.22 , and $\mathrm{P}$ value was not significant. The $95 \%$ confidence rate was $0.38-3.89$, so it had low confidence. Thus, it cannot stand alone as a single predictor of difficult endotracheal intubation. Iohom et al. [19] also stated that rather than using the Mallampati classification alone, using other airway evaluation tests together is more useful in predicting difficult intubation.

The 2 groups showed a significant difference in the chisquare test when the inter-incisor gap and head and neck movement were compared (Table 4); on multiple regression analysis, the odds ratio was 3.11 in the head and neck movement, and 2.32 in the inter-incisor gap. Their odds ratio was higher than the Mallampati classification's odds ratio, but their $\mathrm{P}$ value on multiple regression analysis was not significant. In addition, the $95 \%$ confidence interval was $0.87-11.13$ in the head and neck movement, and 0.75-7.19 in the inter-incisor gap, which means low confidence. So it could not be used alone as a predictor of difficult endotracheal intubation (Table 5).

The thyromental distance $(<6 \mathrm{~cm})$ was not significantly different between the 2 groups (Table 4 ). However, in the other studies $[6,7]$ the thyromental distance was significant in predicting difficult intubation. The authors found during the study process that many patients with small body frames compared to patients with larger frames had relatively short thyromental distances. Therefore, rather than using absolute values and the same standard for all patients, a relative standard based on the Korean mean height should be used for more accurate predictions. The severity of buck teeth $(>0.5 \mathrm{~cm})$ was also not significantly different between the two groups (Table 4). In many cases, there was no difficulty in intubation even if the upper teeth protruded, as long as the mouth could be opened wide.

IDS is made up of 7 measuring variables. The number of intubation attempts, additional procedures performed, and the use of other intubation methods were assessed by the observer. The performer assessed Cormack and Lehane's classification on laryngeal view, the lifting force during laryngoscopy, external laryngeal pressure maneuver, and the location of the vocal cord under laryngoscopic view [14]. This is a mutually complementing system based on an objective standard, where the observer and performer make evaluations together. The measuring variables for IDS are made up of objective questions that are quantifiable so the evaluation can be performed simply in a short time. It is considered far better in specificity than VAS (visual analogue scale), categorical classification, and time [11]. Furthermore, numbers alone can easily be used to judge the difficulty of intubation. So it may be useful for comparative studies on difficult endotracheal intubation. The present study wanted to test the reliability of IDS in assessing the difficulty of intubation, so intubation time and the lowest $\mathrm{SpO}_{2}$ values were taken as additional objective markers. In the DI group, intubation time was significantly longer and the lowest $\mathrm{SpO}_{2}$ value was lower. A high IDS actually signifies a difficult endotracheal intubation. However, when using IDS to study difficult endotracheal intubation, the intubation conditions must be standardized or there must be a great sample size for multiple regression analysis to be possible [11].

In conclusion, using many airway assessment factors and finding TAS $>6$ is a better method than using just one factor when trying to predict difficult intubation. When TAS cannot be found, the ULBT (class III) is a very useful stand-alone test for predicting difficult endotracheal intubation.

\section{References}

1. Mallampati SR, Gatt SP, Gugino LD, Desai SP, Waraksa B, Freiberger D, et al. A clinical sign to predict difficult tracheal intubation: a prospective study. Can Anaesth Soc J 1985; 32: 429-34.

2. Samsoon GL, Young JR. Difficult tracheal intubation: a retrospective study. Anaesthesia 1987; 42: 487-90.

3. Wilson ME, Spiegelhalter D, Robertson JA, Lesser P. Predicting difficult intubation. Br J Anaesth 1988; 61: 211-6.

4. Oates JD, Macleod AD, Oates PD, Pearsall FJ, Howie JC, Murray GD. Comparison of two methods for predicting difficult intubation. $\mathrm{Br} \mathrm{J}$ Anaesth 1991; 66: 305-9.

5. Benumof JL. Management of the difficult adult airway. With special emphasis on awake tracheal intubation. Anesthesiology 1991; 75: 1087-110.

6. Kim DS, Ryn SJ, Kim KH, Jang TH, Kim SH. Evaluation of airway assessment factors for predicting difficult intubation. Korean J Anesthesiol 1997; 32: 51-6.

7. Arne J, Descoins P, Fusciardi J, Ingrand P, Ferrier B, Boudigues D, et al. Preoperative assessment for difficult intubation in general and ENT surgery: predictive value of a clinical multivariate risk index. Br J Anaesth 1998; 80: 140-6.

8. Reed MJ, Dunn MJ, McKeown DW. Can an airway assessment score predict difficulty at intubation in the emergency department? Emerg Med J 2005; 22: 99-102.

9. Soyuncu S, Eken C, Cete Y, Bektas F, Akcimen M. Determination of difficult intubation in the ED. Am J Emerg Med 2009; 27: 905-10.

10. Practice guidelines for management of the difficult airway. A report by the American society of anesthesiologists task force on management of the difficult airway. Anesthesiology 1993; 78: 597602.

11. Adnet F, Borron SW, Racine SX, Clemessy JL, Fournier JL, Plaisance $\mathrm{P}$, et al. The intubation difficulty scale (IDS): proposal and evaluation of a new score characterizing the complexity of endotracheal intubation. Anesthesiology 1997; 87: 1290-7.

12. Khan ZH, Kashfi A, Ebrahimkhani E. A comparison of the upper lip bite test (a simple new technique) with modified Mallampati 
classification in predicting difficulty in endotracheal intubation: a prospective blinded study. Anesth Analg 2003; 96: 595-9.

13. Lee SM, Kim DS, Ryu SJ, Chang TH, Kim SH, Kim KH. The evaluation of predictability of difficult intubation using upper lip bite test. Korean J Anesthesiol 2005; 49: 287-92.

14. Lavi R, Segal D, Ziser A. Predicting difficult airways using the intubation difficulty scale: a study comparing obese and non-obese patients. J Clin Anesth 2009; 21: 264-7.

15. Flegal KM, Carroll MD, Kuczmarski RJ, Johnson CL. Overweight and obesity in the United States: prevalence and trends, 1960-1994. Int J Obes Relat Metab Disord 1998; 22: 39-47.
16. Lee KS, Hwang IC, Kim SS, Kim KK. Perception of obesity and its related factors. Korean J Obes 2009; 18: 116-22.

17. Lee A, Fan LT, Gin T, Karmakar MK, Ngan Kee WD. A systematicreview (meta-analysis) of the accuracy of the Mallampati tests to predict the difficult airway. Anesth Analg 2006; 102: 1867-78.

18. Tham EJ, Gildersleve CD, Sanders LD, Mapleson WW, Vaughan RS. Effects of posture, phonation, and observer on Mallampati classification. Br J Anaesth 1992; 68: 32-8.

19. Iohom G, Ronayne M, Cunningham AJ. Prediction of difficult tracheal intubation. Eur J Anaesthesiol 2003; 20: 31-6. 